\title{
Discriminating Children and Adolescents of Some Affluent Families of Bangladesh by Prevalence of Non-Communicable Diseases Except Diabetes
}

\author{
KC Bhuyan* \\ Professor of Statistics, Jahangirngar University, Bangladesh \\ *Corresponding Author: KC Bhuyan, Professor of Statistics, Jahangirngar University, Bangladesh.
}

Received: June 25, 2019; Published: July 31, 2019

DOI: $10.31080 /$ ASNH.2019.03.0387

\begin{abstract}
The analytical results presented here were prepared using the data collected from 662 children and adolescents who were investigated from 560 randomly selected families of the students of American International University-Bangladesh. It was evident from the analysis that 9.1 percent of the investigated children and adolescents were obese and severe obese and 70.2 percent were underweight. Among the investigated children 13.4 percent were suffering from non-communicable diseases except diabetes and 56.2 percent of them had problem in the eye. The percentage of respondents who were free of other non-communicable diseases was 86.6. Some of the social characters of the children were associated with prevalence of different diseases. The importance of the social characters were identified by discriminant analysis, where discrimination was done by levels of non-communicable diseases except diabetes. The analysis showed that parent's occupation were the most important variables for the discrimination of the respondents by the levels of non-communicable diseases except diabetes.
\end{abstract}

Keywords: Level of Obesity; Prevalence of Different Diseases; Socioeconomic Variables Associated with Different Diseases;

Discriminant Analysis; Identification of Variables Responsible for Different Diseases

\section{Introduction}

Child obesity is a condition where excess body fat negatively affects a child's health or wellbeing and it can lead to life-threatening conditions including diabetes, heart disease, sleep problem, cancer, liver disease, early puberty, eating disorders, skin infections, asthma and other respiratory problem [1-4]. The problems of obesity in adolescence include hepatitis, sleep apnoea, and increased intracranial pressure $[5,6]$ and obese adolescents have the increased chance of mortality during adulthood [7]. The other problems of overweight and obesity are physical and psychological [8]. Children who are obese are likely to be obese as adulthood and risk of child obesity increases with the increase in obesity of both parents. This in turn reflects the family environment. From 1980 to 2013 , the prevalence of overweight and obesity in children increased nearly by 50 percent [8]. Currently 10 percent of children world wide are either obese or overweight [9].
The increasing trend in overweight and obesity are also noted in Bangladesh and these range from $1 \%$ to $17.9 \%$ with higher percentage among urban children for all age groups and sexes [10]. In Bangladesh there is a public health threat which arises from the increasing prevalence of overweight and obesity. This threat is for the children of ages (0-12years) and for the adolescents of ages (13-19 years) [11].

The risk factors for obesity include the use of modern technology, specially, applied in preparing snacks and fast food and the decrease in the physical activity like games and sports. The risk also increases with staying time in the house and using the electronic devices, specially, watching television and using mobile phone. Sometimes parents want their kids stay in the house to avoid the violence, drug, and attack by the gang stars [8]. In the urban area obesity is associated with food intake behavior as members of ur- 
ban family frequently take food at fast food shop $[9,12,13]$. These food are of high calorie and usually contains high level of fat and low level of fiber. The sweetened beverage in fast food shop and/or roadside shop is also a source of obesity [14].

As per the above discussion it was decided to investigate the influencing factors for prevalence of different diseases except diabetes among the children of some affluent families of Bangladesh. The specific objective of the study was to (a) investigate the association of different social factors with prevalence of different diseases except diabetes, (b) to identify the most responsible factors for the prevalence of different diseases through discriminant analysis.

\section{Methodology}

In a separate study $[15,16]$ the students of American International University were reported as members of affluent families and hence to investigate the children and adolescents from affluent families a plan was formulated to select a random sample of students from the university. The selection of students and survey were done during the 2016-17 summer semester. In a separate study [11] it was reported that there were 7 percent obese and overweight children in Bangladesh. Accordingly the plan was formulated to select a sample of required size so that a proportion of 0.07 overweight and obese children could be estimated in such a way that the margin of error could be 0.02 at $95 \%$ confidence. This condition gave a sample size of 625 when the formula was used for simple random sampling. This size of sample covered 6.6 percent students of the university. The sample students were selected by simple random sampling method. The information were collected by the students from their families. The students were specially instructed by the author to collect correct information with the help of their parents. It was expected to get the responses from at least $5 \%$ selected families. Finally, information were available for 662 children and adolescents of 560 families.

For the collection of information a questionnaire was prepared beforehand and it was pretested so that correct information could be recorded properly. In some cases the adolescents filled the questionnaire with the help of their parents and the students who were supposed to collect information. The questionnaire was filled in by any one of the parent when the children were not capable to do that.
The important collected information were residence, religion, age, height, weight, sex, food habit, utilization of time by the child, involvement in co-curricular activities by the children, if it is feasible, prevalence of non-communicable diseases except diabetes etc. To study the socioeconomic background of the children, the information regarding parent's level of education, occupation and income were also collected.

The investigated children and adolescents were classified into 4 groups by level of BMI [weight in $\mathrm{kg} /(\text { height in } \mathrm{m})^{2}$ ] where the level of obesity was decided by percentile value of BMI. The children having BMI above the 85th percentile were considered as overweight and those who had BMI above the 95th percentile were considered as obese [17]. The children having BMI $<23$ which was below 85th percentile was termed as underweight and severe obesity was considered if BMI was greater than 95th percentile but more than 45 . Association of level of prevalence of different diseases of offspring with families' socioeconomic back ground were examined using chi-square test, where significant association was concluded when $p$-value of the chi-square test was $\leq 0.05$.Association of prevalence of other non-communicable diseases was also examined. Responsible variables for the change in the levels of prevalence of other diseases were detected by discriminant analysis [18,19].

\section{Results and Discussion}

The present analysis was done using the data related to social, medical and economic aspects of 662 children of age less than or equal to 18 years investigated from 560 randomly selected families of the students of American International University - Bangladesh.

In this study it was attempted to investigate the prevalence of non-communicable diseases except diabetes among the children and adolescents. The analytical data indicated that 86.6 percent respondents were not affected by any other diseases. The prevalence of other diseases was reported among 13.4 percent children and adolescents. Among them 56.2 percent were facing problem in the eye. Among the severe obese group 33.3 percent were suffering from eye problem. This eye problem was the major component of other diseases. Among 18 children and adolescents of severe obese group 33.3 percent were suffering from eye problem. There was significant association between level of obesity and prevalence of other diseases $\left[\chi^{2}=41.038, p\right.$-value $=0.000$, Table 1$]$. 
Discriminating Children and Adolescents of Some Affluent Families of Bangladesh by Prevalence of Non-Communicable Diseases Except Diabetes

\begin{tabular}{|c|c|c|c|c|c|c|c|c|c|c|c|c|}
\hline \multirow{3}{*}{ Level of obesity } & \multicolumn{10}{|c|}{ Prevalence of other non-communicable diseases } & \multicolumn{2}{|c|}{ Total } \\
\hline & \multicolumn{2}{|c|}{ None } & \multicolumn{2}{|c|}{ Eye problem } & \multicolumn{2}{|c|}{ Kidney problem } & \multicolumn{2}{|c|}{ Hypertension } & \multicolumn{2}{|c|}{ Others } & \multirow{2}{*}{$\mathbf{n}$} & \multirow{2}{*}{$\%$} \\
\hline & $\mathbf{n}$ & $\%$ & $\mathbf{n}$ & $\%$ & $\mathbf{n}$ & $\%$ & $\mathbf{n}$ & $\%$ & $\mathbf{n}$ & $\%$ & & \\
\hline Underweight & 412 & 88.6 & 32 & 6.9 & 4 & 0.9 & 7 & 1.5 & 10 & 2.2 & 465 & 70.2 \\
\hline Overweight & 118 & 86.1 & 9 & 6.6 & 1 & 0.7 & 1 & 0.7 & 8 & 5.8 & 137 & 20.7 \\
\hline Obese & 32 & 76.2 & 3 & 7.1 & 0 & 0.0 & 0 & 0.0 & 7 & 16.7 & 42 & 6.3 \\
\hline Severe obese & 11 & 61.1 & 6 & 33.3 & 0 & 0.0 & 0 & 0.0 & 1 & 5.6 & 18 & 2.7 \\
\hline Total & 573 & 86.6 & 50 & 7.6 & 5 & 0.8 & 8 & 1.2 & 26 & 3.9 & 662 & 100.0 \\
\hline
\end{tabular}

Table 1: Distribution of children and adolescents according to their level of obesity and prevalence of other non-communicable diseases.

The main objective was to discriminate the children and adolescents by the prevalence of non-communicable diseases except diabetes. Now, let us investigate the association of level of obesity and level of other diseases with social factors prevailed among children and adolescents. The different diseases were eye problem, kidney problem, hypertension and some other diseases. The eye problem was reported by 7.6 percent children. The eye problem was the major one for the respondents.
Amongst the studied children 15.6 percent were of age 5 - 10 years (Table 2) and 11.4 percent of them were suffering from eye problem. The corresponding percentages of children with eye problem among the other two groups of other two ages were less. There was significant association between age of children and adolescents with prevalence of other diseases $\left[\chi^{2}=27.990\right.$, $\mathrm{p}$-value $=0.000]$.

\begin{tabular}{|c|c|c|c|c|c|c|c|c|c|c|c|c|}
\hline \multirow{3}{*}{$\begin{array}{l}\text { Age } \\
\text { (in years) }\end{array}$} & \multicolumn{10}{|c|}{ Prevalence of other non-communicable diseases } & \multicolumn{2}{|c|}{ Total } \\
\hline & \multicolumn{2}{|c|}{ None } & \multicolumn{2}{|c|}{ Eye problem } & \multicolumn{2}{|c|}{ Kidney problem } & \multicolumn{2}{|c|}{ Hypertension } & \multicolumn{2}{|c|}{ Others } & \multirow{2}{*}{$\mathbf{n}$} & \multirow{2}{*}{$\%$} \\
\hline & $\mathbf{n}$ & $\%$ & $\mathbf{n}$ & $\%$ & $\mathbf{n}$ & $\%$ & $\mathbf{n}$ & $\%$ & $\mathbf{n}$ & $\%$ & & \\
\hline$<5$ & 33 & 78.6 & 4 & 9.5 & 0 & 0.0 & 0 & 0.0 & 5 & 11.9 & 42 & 6.3 \\
\hline $5-10$ & 81 & 78.6 & 12 & 11.7 & 0 & 0.0 & 0 & 0.0 & 10 & 9.7 & 103 & 15.6 \\
\hline $10^{+}$ & 459 & 88.8 & 34 & 6.6 & 5 & 1.0 & 8 & 1.5 & 11 & 2.1 & 517 & 78.1 \\
\hline Total & 573 & 86.6 & 50 & 7.6 & 5 & 0.8 & 8 & 1.2 & 26 & 3.9 & 662 & 100.0 \\
\hline
\end{tabular}

Table 2: Distribution of children and adolescents according to their age and prevalence of other non-communicable diseases.

\begin{tabular}{|c|c|c|c|c|c|c|c|c|}
\hline \multirow{3}{*}{$\begin{array}{l}\text { Prevalence of other non- } \\
\text { communicable diseases }\end{array}$} & \multicolumn{6}{|c|}{ Residence } & \multicolumn{2}{|c|}{ Total } \\
\hline & \multicolumn{2}{|c|}{ Urban } & \multicolumn{2}{|c|}{ Rural } & \multicolumn{2}{|c|}{ Semi-urban } & \multirow{2}{*}{$\mathbf{n}$} & \multirow{2}{*}{$\%$} \\
\hline & $\mathbf{n}$ & $\%$ & $\mathbf{n}$ & $\%$ & $\mathbf{n}$ & $\%$ & & \\
\hline None & 409 & 85.2 & 111 & 93.3 & 53 & 84.1 & 573 & 86.6 \\
\hline Problem of eye & 45 & 9.4 & 3 & 2.5 & 2 & 3.2 & 50 & 7.6 \\
\hline Problem of kidney & 2 & 0.4 & 1 & 0.8 & 2 & 3.2 & 5 & 0.8 \\
\hline Hypertension & 8 & 1.7 & 0 & 0.0 & 0 & 0.0 & 8 & 1.2 \\
\hline Others & 16 & 3.3 & 4 & 3.4 & 6 & 9.5 & 26 & 3.9 \\
\hline Total & 480 & 72.5 & 119 & 18.0 & 63 & 7.5 & 662 & 100.0 \\
\hline
\end{tabular}

Table 3: Distribution of children and adolescents according to their residence and prevalence of other non-communicable diseases. 
It was seen that 72.5 percent children and adolescents were from urban area and 85.2 percent of them had no health hazard. But 9.4 percent of them was facing eye problem. The corresponding percentages among rural and semi-urban children were less. It had already been mentioned that only 13.4 percent respondents were suffering from different types of diseases and majority of them were facing the problem with eye. The eye problem was noted among the majority of (63.4\%) the urban children who were suffering from health hazard. There was significant differences in the prevalence of other diseases among the children of different residential areas $\left[\chi^{2}=22.671 \mathrm{p}\right.$-value $\left.=0.004\right]$.

\begin{tabular}{|c|c|c|c|c|c|c|c|c|c|c|}
\hline \multirow{3}{*}{$\begin{array}{l}\text { Prevalence of other non- } \\
\text { comminicable diseases }\end{array}$} & \multicolumn{8}{|c|}{ Utilization of time } & \multicolumn{2}{|c|}{ Total } \\
\hline & \multicolumn{2}{|c|}{ Study } & \multicolumn{2}{|c|}{ Watch T.V. } & \multicolumn{2}{|c|}{ Sleep } & \multicolumn{2}{|c|}{ Others } & \multirow{2}{*}{$\mathbf{n}$} & \multirow{2}{*}{$\%$} \\
\hline & $\mathbf{n}$ & $\%$ & $\mathbf{n}$ & $\%$ & $\mathbf{n}$ & $\%$ & $\mathbf{n}$ & $\%$ & & \\
\hline None & 101 & 90.2 & 228 & 86.4 & 82 & 73.9 & 162 & 92.6 & 573 & 86.6 \\
\hline Problem of eye & 6 & 6.4 & 28 & 10.6 & 13 & 11.7 & 3 & 1.7 & 50 & 7.6 \\
\hline Problem of kidney & 0 & 0.0 & 2 & 0.8 & 3 & 2.7 & 0 & 0.0 & 5 & 0.8 \\
\hline Hypertension & 0 & 0.0 & 0 & 0.0 & 6 & 5.4 & 2 & 1.1 & 8 & 1.2 \\
\hline Others & 26 & 4.5 & 6 & 2.3 & 7 & 6.3 & 8 & 4.6 & 26 & 3.9 \\
\hline Total & 112 & 16.9 & 264 & 39.9 & 111 & 16.8 & 175 & 26.4 & 662 & 100.0 \\
\hline
\end{tabular}

Table 4: Distribution of children and adolescents according to their utilization of time and prevalence of other non-communicable diseases.

It was observed that 16.9 percent children and adolescents were devoted in their study outside the school hours and 90.2 percent of them had no physical problem Only 6.4 percent of them had eye problem. Majority (39.9\%) of the respondents were spending their time by watching television outside the study hour. Among this group 13.6 percent were facing health hazard of at least one and 77.8 percent of them had eye problem. Eye problem was also dominant among those who killed their time by sleeping. Significant differences in the health problem were noted among the respondents who utilized time differently $[=49.556$, $p$-value $=0.000]$. The children of affluent families, specially, who are living in the city center are more prone to be stay back in the house and kill time by watching television or doing sedentary activities. This fact was noted in a separate study [20]. Moreover children of this type of families are not generally allowed to go outside alone as parent is afraid of gang star and drug [8]. These children also have more chances to frequently visit fast food shops. Their parents can afford the cost of fast foods and they usually try to fulfill the demand of their children if they have sufficient family income.
The food habit of the investigated children and adolescent was one of the responsible factors for obesity [5]. From his study it was noted that obesity and prevalence of other diseases were associated. Hence food habit and prevalence of others diseases were expected to be associated. Majority (72.5\%) of the children were from city center and they were selected from a population of families who were identified as affluent city residence $[15,16]$. So the children and adolescents of these families had the scope to get sufficient foods, with proper hygienic measure. A big group (47.9\%) of respondents were habituated in taking food from restaurants but 87.4 percent of them had no health problem. The corresponding percentages among those who were taking much more rice, rice/ fish and meat were almost similar (Table 5). Those who had any type of health problem 38.2 percent of them had eye problem and these group were taking much more rice, fish and meat. However, food habit and prevalence of other diseases were not associated $\left[\chi^{2}\right.$ $=10.441$, p-value $=0.235]$. 


\begin{tabular}{|l|c|c|c|c|c|c|c|c|}
\hline \multirow{2}{*}{$\begin{array}{l}\text { Prevalence of other non- } \\
\text { communicable diseases }\end{array}$} & \multicolumn{9}{|c|}{ Food habit } & \multicolumn{2}{c|}{ Total } \\
\cline { 2 - 9 } & \multicolumn{2}{|c|}{ Much more rice } & \multicolumn{2}{|c|}{$\begin{array}{c}\text { More rice/fish } \\
\text { and meat }\end{array}$} & \multicolumn{2}{c|}{ Restaurant food } & \multirow{2}{*}{ n } & \multirow{2}{*}{$\%$} \\
\cline { 2 - 9 } & $\mathbf{n}$ & $\mathbf{\%}$ & $\mathbf{n}$ & $\mathbf{\%}$ & $\mathbf{n}$ & $\mathbf{\%}$ & & \\
\hline None & 68 & 87.2 & 228 & 85.4 & 277 & 87.4 & 573 & 86.6 \\
\hline Eye problem & 7 & 9.0 & 24 & 9.0 & 19 & 6.0 & 50 & 20.7 \\
\hline Kidney problem & 0 & 0.0 & 2 & 0.7 & 3 & 0.9 & 5 & 6.3 \\
\hline Hypertension & 1 & 1.3 & 6 & 2.2 & 1 & 0.3 & 8 & 2.8 \\
\hline Others & 2 & 2.6 & 7 & 2.6 & 17 & 5.4 & 26 & 100 \\
\hline Total & 78 & 11.8 & 267 & 40.3 & 317 & 47.9 & 662 & 100.0 \\
\hline
\end{tabular}

Table 5: Distribution of children and adolescents according to their food habit and prevalence of other non-communicable diseases.

It was observed that the monthly family income of $38.2 \%$ families was 70 thousand and above taka [Bangladesh currency] but 86.6 percent children of these families were not facing any health problem (Table 6). Health hazard was minimum among the children of those families who had income at least sixty thousand taka. Eye problem was dominant among the children of families of lower income. Among the children of lower income families 41.6 percent were facing health problem. This proportion was 0.382 for the children of higher income group of families. The differentials in proportions according to prevalence of other diseases and family income were significant $\left[\chi^{2}=34.675\right.$, $p$-value $\left.=0.000\right]$.

\begin{tabular}{|c|c|c|c|c|c|c|c|c|c|c|}
\hline \multirow{3}{*}{$\begin{array}{l}\text { Prevalence of other non- } \\
\text { communicable diseases }\end{array}$} & \multicolumn{8}{|c|}{ Monthly family income (in 000 taka) } & \multicolumn{2}{|c|}{ Total } \\
\hline & \multicolumn{2}{|c|}{$<40$} & \multicolumn{2}{|c|}{$40-60$} & \multicolumn{2}{|c|}{$60-70$} & \multicolumn{2}{|c|}{$\mathbf{7 0}^{+}$} & \multirow{2}{*}{$\mathbf{n}$} & \multirow{2}{*}{$\%$} \\
\hline & $\mathbf{n}$ & $\%$ & $\mathbf{n}$ & $\%$ & $\mathbf{n}$ & $\%$ & $\mathbf{n}$ & $\%$ & & \\
\hline None & 160 & 81.2 & 56 & 82.4 & 138 & 95.8 & 219 & 86.6 & 465 & 70.24 \\
\hline Eye problem & 26 & 13.2 & 6 & 8.8 & 4 & 2.8 & 14 & 5.5 & 137 & 20.69 \\
\hline Kidney problem & 3 & 1.5 & 0 & 0.0 & 0 & 0.0 & 2 & 0.8 & 42 & 6.3 \\
\hline Hypertension & 1 & 0.5 & 0 & 0.0 & 0 & 0.0 & 7 & 2.8 & 18 & 2.72 \\
\hline Others & 7 & 3.6 & 6 & 8.8 & 2 & 1.4 & 11 & 4.3 & 662 & 100 \\
\hline Total & 197 & 29.8 & 68 & 10.2 & 144 & 21.8 & 253 & 38.2 & 662 & 100.0 \\
\hline
\end{tabular}

Table 6: Distribution of children and adolescents according to prevalence of other non-communicable diseases and monthly family income.

It was seen that prevalence rate of obesity as well as prevalence rate of other diseases were higher among the children of low income group of families. The behavior of obesity and prevalence of other diseases were significantly different among the low income group of families. This indicated that family environment was one of the correlates of obesity among children [21] and also was one of the correlates of prevalence of other diseases. But family environment was influenced by parents' education and occupation. Let us investigate how fathers' and mothers' education were associated with children and adolescents prevalence of other diseases. However, father's education was not found associated with prevalence of other diseases and this result was not shown. But mother's 
education and prevalence of other diseases of children and adolescents were significantly associated $\left[\chi^{2}=45.058\right.$, $p$-value $=0.000$, Table 7]. Majority (55.9\%) mothers were higher educated and 91.4 percent children of these mothers did not face any type of health hazard. A bigger number of mothers (32.3\%) were educated up to secondary level but the children of these mothers were worst sufferer in respect of health problem. Eye problem was dominant among the children of this group of mothers.

\begin{tabular}{|c|c|c|c|c|c|c|c|c|c|c|}
\hline \multirow{3}{*}{$\begin{array}{l}\text { Prevalence of other non- } \\
\text { communicable diseases }\end{array}$} & \multicolumn{8}{|c|}{ Mother's education } & \multicolumn{2}{|c|}{ Total } \\
\hline & \multicolumn{2}{|c|}{ Illiterate } & \multicolumn{2}{|c|}{ Primary } & \multicolumn{2}{|c|}{ Secondary } & \multicolumn{2}{|c|}{ Higher } & \multirow{2}{*}{$\mathbf{n}$} & \multirow{2}{*}{$\%$} \\
\hline & $\mathbf{n}$ & $\%$ & $\mathbf{n}$ & $\%$ & $\mathbf{n}$ & $\%$ & $\mathbf{n}$ & $\%$ & & \\
\hline None & 35 & 89.7 & 36 & 92.3 & 164 & 76.6 & 338 & 91.4 & 573 & 86.6 \\
\hline Eye problem & 0 & 0.0 & 1 & 2.6 & 31 & 14.5 & 18 & 4.9 & 50 & 7.6 \\
\hline Kidney problem & 0 & 0.0 & 0 & 0.0 & 4 & 1.9 & 1 & 0.3 & 5 & 0.8 \\
\hline Hypertension & 1 & 2.6 & $0-$ & 0.0 & 7 & 3.3 & 0 & 0.0 & 8 & 1.2 \\
\hline Others & 3 & 7.7 & 2 & 5.1 & 8 & 3.7 & 13 & 3.5 & 26 & 3.9 \\
\hline Total & 39 & 5.9 & 39 & 5.9 & 214 & 32.3 & 370 & 55.9 & 662 & 100.0 \\
\hline
\end{tabular}

Table 7: Distribution of children and adolescents according to prevalence of other non-communicable diseases and level of mother's education.

Father's occupation was significantly associated with the prevalence of other diseases of children and adolescents [Table 8, $=35.493, \mathrm{p}$-value $=0.000]$. It was noted that 44.6 percent fathers were businessmen and 9.5 percent children of these fathers had the eye problem. The eye problem was noted in lower percentage among children of fathers having profession other than agriculture, business and service. Next lower proportion of children having eye problem was noted among the children in agriculture family.

\begin{tabular}{|c|c|c|c|c|c|c|c|c|c|c|}
\hline \multirow{3}{*}{$\begin{array}{l}\text { Prevalence of other non- } \\
\text { communicable diseases }\end{array}$} & \multicolumn{8}{|c|}{ Father's occupation } & \multicolumn{2}{|c|}{ Total } \\
\hline & \multicolumn{2}{|c|}{ Agriculture } & \multicolumn{2}{|c|}{ Business } & \multicolumn{2}{|c|}{ Service } & \multicolumn{2}{|c|}{ Others } & \multirow{2}{*}{$\mathbf{n}$} & \multirow{2}{*}{$\%$} \\
\hline & $\mathbf{n}$ & $\%$ & $\mathbf{n}$ & $\%$ & $\mathbf{n}$ & $\%$ & $\mathbf{n}$ & $\%$ & & \\
\hline None & 30 & 88.2 & 247 & 83.7 & 265 & 89.8 & 31 & 81.6 & 573 & 86.6 \\
\hline Eye problem & 2 & 5.9 & 28 & 9.5 & 18 & 6.1 & 2 & 5.3 & 50 & 7.6 \\
\hline Kidney problem & 0 & 0.0 & 3 & 1.0 & 2 & 0.7 & 0 & 0 & 5 & 0.8 \\
\hline Hypertension & 0 & 0.0 & 3 & 1.0 & 1 & 3.4 & 4 & 10.5 & 8 & 1.2 \\
\hline Others & 2 & 5.9 & 14 & 4.7 & 9 & 3.1 & 1 & 2.6 & 26 & 3.9 \\
\hline Total & 34 & 3.6 & 295 & 44.6 & 295 & 44.6 & 38 & 7.2 & 662 & 100.0 \\
\hline
\end{tabular}

Table 8: Distribution of children and adolescents according to their father's occupation and prevalence of other non-communicable diseases.

In a separate study, it was observed that mothers occupation and level of obesity of children and adolescents were significantly associated [20]. Here investigation was done to study the association of prevalence of other diseases with mother's occupation. Most of the mothers were housewives (86.9\%) and 8.2 percent children of these mothers were facing eye problem. High blood pressure was observed among 8 children and 7 out of these 8 children were from families in which mothers were service women. Significant association was noted between mother's occupation and prevalence of other diseases $\left[\chi^{2}=48.263\right.$, $p$-value $\left.=0.000\right]$. 
Discriminating Children and Adolescents of Some Affluent Families of Bangladesh by Prevalence of Non-Communicable Diseases Except Diabetes

\begin{tabular}{|c|c|c|c|c|c|c|c|c|}
\hline \multirow{3}{*}{$\begin{array}{l}\text { Prevalence of other non- } \\
\text { communicable diseases }\end{array}$} & \multicolumn{6}{|c|}{ Mother's occupation } & \multicolumn{2}{|c|}{ Total } \\
\hline & \multicolumn{2}{|c|}{ Housewife } & \multicolumn{2}{|c|}{ Others } & \multicolumn{2}{|c|}{ Service } & \multirow[t]{2}{*}{ No } & \multirow[t]{2}{*}{$\%$} \\
\hline & No. & $\%$ & No. & $\%$ & No. & $\%$ & & \\
\hline None & 501 & 87.1 & 5 & 83.3 & 67 & 82.7 & 573 & 86.6 \\
\hline Eye problem & 47 & 8.2 & 0 & 0.0 & 3 & 3.7 & 50 & 7.6 \\
\hline Kidney problem & 5 & 0.9 & 0 & 0.0 & 0 & 0.0 & 5 & 0.8 \\
\hline Hypertension & 1 & 0.2 & 0 & 0.0 & 7 & 8.6 & 8 & 1.2 \\
\hline Others & 21 & 3.7 & 1 & 16.7 & 4 & 4.9 & 26 & 3.9 \\
\hline Total & 575 & 86.9 & 6 & 0.9 & 81 & 12.2 & 662 & 100.0 \\
\hline
\end{tabular}

Table 9: Distribution of children and adolescents according to the prevalence of other non-communicable diseases and level of mother's occupation.

\section{Discriminant analysis}

From the analysis presented above it was noted that there was significant association between prevalence of other diseases and some of the social characters of the children and adolescents. But most responsible factors for enhancing the diseases were not identified by the study of association of two factors. The most responsible factors can be identified by discriminant analysis [19] when discrimination is done among different groups of respondents. In the present analysis, the total investigated children and adolescents were classified into 5 groups according to the prevalence of diseases. The socioeconomic characteristics of different groups were significantly different. It was investigated by one way analysis of variance before performing discriminant analysis.

The results of the analysis were shown below

\begin{tabular}{|l|c|c|c|}
\hline Variable & $\begin{array}{c}\text { Wilk's } \\
\text { Lambda }\end{array}$ & F- value & p-value \\
\hline Residence & 0.974 & 4.336 & 0.002 \\
\hline Religion & 0.990 & 1.590 & 0.175 \\
\hline Age of children & 0.963 & 6.275 & 0.000 \\
\hline Gender & 0.999 & 0.204 & 0.936 \\
\hline Father's education & 0.987 & 2.153 & 0.073 \\
\hline Mother's education & 0.990 & 1.648 & 0.161 \\
\hline Father's occupation & 0.986 & 2.331 & 0.055 \\
\hline Mother's occupation & 0.933 & 11.714 & 0.000 \\
\hline Family income & 0.977 & 3.813 & 0.004 \\
\hline Food habit of child & 0.987 & 2.226 & 0.065 \\
\hline Utilization of time by the child & 0.969 & 5.312 & 0.000 \\
\hline BMI & 0.960 & 6.872 & 0.000 \\
\hline
\end{tabular}

Table a
It was noted that except religion, gender and mother's education of the children all other socioeconomic variables of the respondents were almost significantly different for 5 groups of children and adolescents. Except these 3 variables the other variables included in the discriminant analysis were residence, age of children, father's education and occupation, mother's occupation, family income, food habit of child, utilization of time by the child and BMI of the child. The mean vectors of these variables were significantly different as was observed by Box's M-test, where $\mathrm{M}=358.881, \mathrm{~F}=$ 3.854 with $p$-value $=0.000$. This result indicated that discriminant analysis was satisfactory. The results were shown below

\begin{tabular}{|l|c|c|c|}
\hline Variable & $\begin{array}{c}\text { Coefficient of } \\
\text { function-1 }\end{array}$ & $\begin{array}{c}\text { Coefficient } \\
\text { of function-2 }\end{array}$ & $\begin{array}{c}\text { Coefficient } \\
\text { of function-3 }\end{array}$ \\
\hline Residence & 0.108 & -0.493 & 0.036 \\
\hline Age & 0.092 & 0.345 & -0.860 \\
\hline $\begin{array}{l}\text { Father's } \\
\text { education }\end{array}$ & -0.338 & 0.355 & -0.018 \\
\hline $\begin{array}{l}\text { Father's } \\
\text { occupation }\end{array}$ & 0.330 & 0.149 & -0.211 \\
\hline $\begin{array}{l}\text { Mother's } \\
\text { occupation }\end{array}$ & 0.650 & 0.282 & 0.314 \\
\hline Family income & 0.331 & -0.546 & 0.035 \\
\hline $\begin{array}{l}\text { Food habit of } \\
\text { child }\end{array}$ & -0.049 & -0.428 & 0.156 \\
\hline $\begin{array}{l}\text { Utilization of } \\
\text { time by the } \\
\text { child }\end{array}$ & 0.467 & 0.179 & 0.249 \\
\hline BMI & -0.305 & 0.398 & 0.385 \\
\hline
\end{tabular}

Table b 
As there were 5 groups of children according to 5 types of health hazard, 4 discriminant functions were derived. All functions were not significantly different. The results of the test of functions were presented below

\begin{tabular}{|l|c|c|c|}
\hline Test of functions & Wilk's $\boldsymbol{\Lambda}$ & $\boldsymbol{\chi} \mathbf{2}$ & $\mathbf{p}$-value \\
\hline 1 through 4 & 0.767 & 172.93 & 0.000 \\
\hline 2 through 4 & 0.862 & 96.69 & 0.000 \\
\hline 3 through 4 & 0.942 & 38.96 & 0.001 \\
\hline 4 & 0.984 & 10.58 & 0.102 \\
\hline
\end{tabular}

Table c
It was noted that the function 4 was not significant and hence related results to it were not presented. For the discrimination between the functions some variables were detected as the most important one. The important variable was decided by the largest correlation coefficients between discriminant score and a variable. These correlation coefficients were shown below: From the results it was noted that parent's occupation were the most important variables for the discrimination between first and fourth functions.

\begin{tabular}{|l|c|c|c|}
\hline Variable & $\begin{array}{c}\text { Correlation coefficient for } \\
\text { first function }\end{array}$ & $\begin{array}{c}\text { Correlation coefficient for } \\
\text { second function }\end{array}$ & $\begin{array}{c}\text { Correlation coefficient for third } \\
\text { function }\end{array}$ \\
\hline Residence & 0.031 & -0.468 & -0.016 \\
\hline Age & 0.135 & 0.251 & $-0.820^{*}$ \\
\hline Father's education & -0.087 & $0.354^{*}$ & 0.030 \\
\hline Father's occupation & $-0.280^{*}$ & 0.152 & -0.207 \\
\hline Mother's occupation & $0.703^{*}$ & 0.271 & 0.237 \\
\hline Family income & 0.375 & -0.126 & -0.213 \\
\hline Food habit of child & -0.101 & $-0.358^{*}$ & 0.091 \\
\hline Utilization of time by the child & 0.370 & 0.216 & 0.309 \\
\hline BMI & -0.366 & $0.496^{*}$ & 0.241 \\
\hline
\end{tabular}

Table d

*Indicated importance of the variable

The second function discriminated well from forth function and the responsible variables for this function were father's education, food habit of child and BMI. The third function discriminated well from fourth function and the responsible variables were age of children.

\section{Conclusion}

The present study was conducted to observe the prevalence of diseases other than diabetes among the children and adolescents of some randomly selected families of the students of American International University - Bangladesh. Most of the families were city dwellers and these families were socially and economically in better position [15] compared to the general people of Bangladesh. However, the obesity and severe obesity among children were similar to that of the general people of the country [10]. Prevalence of other non-communicable diseases and level of obesity were significantly associated. Severe obesity was associated with the parent's social and economic status and hence prevalence of other diseases was also associated with the parents' social and economic status. Occupation, family income of parents'of children and youth were the most important factors to influence the prevalence of different types of diseases. A big group of children and adolescents suffering from other non-communicable diseases had the problem with eye. The study indicated that prevalence of other diseases was dependent on level of obesity and both these characteristics were the problem for both parents and health planners.

To avoid the problem of obesity and problem of obesity related diseases parents can take care of foods of their offspring and can motivate them to take home foods as per as possible avoiding the 
restaurant foods. They can motivate their kids to reduce the sedentary activities like use of electronic devices, viz. video games, smart phone, television etc. as per as possible so that they can spend their more times in doing some activities related to physical work in addition to their academic works.

Some social policies may be recommended for the beneficial of the children's health [22]. These are

- There should be quality school lunch,

- Motivation to avoid calorie-dense snacks and sweetened beverages,

- $\quad$ There should be access to fresh and healthy affordable food [23],

- Emphasis should be given on schools' physical activities,

- $\quad$ There should be prevalence of access to parks and playgrounds,

- Parents can accompany the kids to go outside on foot, whenever possible,

- $\quad$ There should be scope for screening obesity for the children of age $6+$ years [24].

\section{Bibliography}

1. Obesity: Complications, Mayo Clinic.

2. Kopelman Peter G. "Clinical obesity in adults and children". In Adults and Children, Blackwell Publishing (2005).

3. Anna MG and Sonia Caprio. "Obesity in children and adolescents". The Journal of Clinical Endocrinology and Metabolism 93 (2008): 531-536.

4. Daniels S. "The consequence of childhood overweight and obesity". Future Child 16 (2006): 47-67.

5. Must A and Strauss RS. "Risk and consequences of childhood and adolescent obesity”. Social Work 58 (1999): 241-52.

6. Must A., et al. "A follow-up of the Harvard Growth Study of 1922 - 1935". The New England Journal of Medicine 327 (1992): 1350-1355.

7. Pulgaron ER. "Child obesity: a review of increased risk for physical and psychological combordities". Clinical Therapy 35 (2013): A 18-A 32.
8. Ng Marie., et al. "Global, regional and national prevalence of overweight and obesity in children and adults during 19802013; a systematic analysis for the global burden of diseases study 2013". The Lancet 384 (2014): 766-781

9. Bassesen DH. "Update on obesity". The Journal of Clinical Endocrinology and Metabolism 93 (2008): 2027-34.

10. Rahman S., et al. "Obesity and Overweight in Bangladeshi Children and Adolescents: a scoping review". BMC Public Health 14 (2014): 70.

11. Biswas T., et al. "Overweight and obesity among children and adolescents in Bangladesh: a systematic review and metaanalysis". Public Health 142 (2017): 94-101.

12. Emmett Pauline M and Jone LR. "Diet, growth and obesity development throughout childhood in the Avon Longitudinal Study of parents and children". Nutrition Reviews 73 (2015): 175-206.

13. James J and Kerr D. "Prevention of childhood obesity by reducing soft drinks". International Journal of Obesity [land], 29 (2005): S54-57.

14. Naude CE., et al. "Effects of total fat intake on body weight in children”. Cochrane Data Base of Systematic Reviews (2018).

15. Mahfuza K and Bhuyan KC. "Awareness of health hazard of tobacco consumption among students of American International University-Bangladesh". AJSE 13 (2014): 85-92.

16. Hoque ME., et al. "Prevalence of overweight and obesity among children and adolescents of the Indian subcontinent: A meta analysis approach". Nutrition Review 77 (2014): 542-550.

17. Healthy Weight: Assessing your weght: BMI: for children and teens (2019).

18. Bhuyan KC. "A note on the application of discriminant analysis in medical research". Archives of diabetes and obesity 2 (2019): $142-146$

19. Bhuyan KC. Multivariate Analysis and its Applications, New Central Book Agency(p) Ltd (2004).

20. Urmi FA and Bhuyan KC. "Identification of factors responsible for obesity in children and adolescents of some affluent families". BJSTR 10 (2018). 
21. Ray JW and Klesges RC. "Influences on the eating behavior of the children". Annals of the New York Academy of Sciences 699 (1993): 57-69.

22. Berger Kathleen Stassen. Invitation to the Life Span, Second Edition, Worth Publishers, New York (2014).

23. Howlett E., et al. From Food Desert Food Oasis: The Potential Influence of Food Retailers on Childhood Obesity Rates, Springer 139 (2015): 215-224.

24. Grossman DC., et al. "Screening of obesity in childhood and adolescents, U.S. Preventive Services Task Force Recommendation Statement". JAMA 317 (2017): 2417-2426.

Volume 3 Issue 8 August 2019

(C) All rights are reserved by KC Bhuyan. 